\title{
Adoption of production technologies by potato growers in northwest Bangladesh
}

\author{
A.B.M. Sharif $\operatorname{Uddin}^{1}$, M.M. Rahman ${ }^{2 *}$, M.B. Alam ${ }^{3}$ and M.H.K. Kamaly ${ }^{4}$ \\ 1, 3 \& 4 Institute of Bangladesh Studies, University of Rajshahi, Rajshahi 6205, \\ Bangladesh; ${ }^{2}$ Department of Agronomy \& Agricultural Extension, University of \\ Rajshahi, Rajshahi 6205, Bangladesh. \\ * Corresponding author: mostafizur2001@yahoo.com
}

\begin{abstract}
Determining the extent of adoption of modern variety potato production technologies by the potato growers was the main focus of the study. The study was conducted in the Rajshahi district. Out of 1547 potato growers, 232 respondents were randomly selected as a sample for data collection from twenty villages. A pre-tested interview schedule was used to collect data from the respondents during July 2010 to February 2011. For measuring the adoption of modern variety potato production technologies by the potato growers, 11 technologies on modern potato production were considered. Majority $(46.55 \%)$ of the growers had medium adoption compared to high (29.74\%) and low (23.71\%) adoption. Among the extent of adoption of eleven selected technologies recommended 'irrigation' was at top highest ranking as indicated by the adoption index where as plant spacing was bottom lowest. The adoption variations in different technologies will not be improved unless effective steps are taken to increase growers' exposure to get benefits of using such technologies as per recommendations.
\end{abstract}

Keywords: Adoption, production, technologies, potato, growers.

\section{Introduction}

Potato is the major vegetable crop in Bangladesh as well as one of the major cash crops cultivated more or less in winter all over the country. Potato ranks first among the vegetables in Bangladesh both in area and production. It ranks among the four most important food crops in the world including wheat, rice and corn (Van-Dipen, 2003). People of at least 40 countries eat potato as their staple food (Islam, 1993). The world production of potato in the year of 1998, 1999 and 2000 were 299.31, 297.17 and 311.28 million metric ton, respectively and the area coverage were18.82, 18.98 and 18.76 million hectares. The yield record was 15.90, 15.65 and 16.59 ton/hectare (FAO, 2002). In Bangladesh, per hectare average yield of paddy, wheat and potato is 1282, 1782 and 10,160 kg respectively (BBS, 1982). There is a possibility to increase per hectare yield of potato in comparison to other crops. So potato is still a promising crop. Bangladesh has made a visible progress in potato production during 1950-51 to 2007-08. Area under potato has increased to double and production has also risen to double during the same period. Potato cultivation has been getting popular in Bangladesh over the last several years. The soil and climatic condition of Bangladesh is very suitable for potato cultivation with mere chance of natural disasters unlike of 
Kharip seasonal crops. Potato takes only 90 to 115 days for maturity, early varieties of potato can be harvested after 75 days of plantation. Though production cost is high, farmers can easily draw profit through cultivation of potato. Net return from any other winter crop than potato is not exceeding. That is why potato has a greater contrast acceptance to the growers' level. Possibility of raising yield is far greater in potato than rice and wheat (Rashid, 1987).

In Bangladesh, Northwest Crop Diversification Project (NCDP) has prescribed high value crop production technologies in 2007 and told in its preface that the soil and climate of northwest Bangladesh is in favour of many fruits and vegetables but yield per hectare is low. The reason of low yield is lack of overall information regarding modern HYV and inappropriate use of modern production technologies. Resource constraints and limitations of knowledge on production technologies by the small and marginal farmers are also responsible for low yield. The entire crop production depends on the traditional systems. The net cultivable land would be decreased from 8.42 million ha in 2000 to 7.89 million ha in 2025 and population would be increased from 127.22 million in 2000 to 168.89 million in 2025 (Bhuiyan et al., 2002). Potato cultivation has been getting popular in Bangladesh over last several years. Possibility of raising yield is greater in potato than rice and wheat. The soil and climate of Bangladesh is good enough to support potato yields more than 25 ton/ha but the actual yield is 15 ton/ha (Rashid, 1987). Adoption of modern potato technologies by the growers will increase production and thereby will improve their-living standard. In view of the foregoing discussion, the study was designed to find out of extent of adoption of potato production technologies by the potato growers.

\section{Materials and methods}

Study area, population and sample

The study was conducted in the Rajshahi district: a northwest area of Bangladesh. Three upazilla namely, Mohonpur, Bagmara and Durgapur from this district were selected considering their production and area under potato cultivation. Finally, six villages from Mohonpur, ten from Bagmara and four from Durgapur were selected randomly as the specific locale of the study. Total number of farmers who had at least 0.13 hectare of land for potato cultivation in these 20 selected villages was 1547 which constituted the population of the study, whilst 232 potato growers were selected randomly as the sample of the study which accounts for 15 percent of the population. Data were collected during the month of July 2010 to February 2011.

\section{Measurement of adoption of modern variety potato}

Based on available literature on the selection of potato production technologies (Muttaleb, 1995; Hasan, 2003; Farukh 2007), field visit and discussion with resource person of Department of Agricultural Extension (DAE), the researcher selected 11 technologies for studying in this investigation. These are (i) land preparation, (ii) cultivation of modern variety, (iii) fertilizer dose, (iv) fertilizer application method, (v) irrigation, (vi) plant protection measures, (vii) quality seed, (viii) inter cultural operations, (ix) planting time, (x) seed size, and (xi) planting space. Procedure for computing score for adoption of each of the eleven 
technologies and the score for overall adoption of the eleven technologies are described as follows:

Well land preparation: Ploughing depth and smoothness of cultured soil provide predisposition of potato cultivation. Land preparation score could range from 0 to 6 , where 0 indicated non adoption of good ground preparation and 6 indicated high adoption of proper land preparation.

Modern variety cultivation score: If the modern variety (MV) potato cultivated area covers up to $10 \%$ of the total cultivated area could score 01 and every $10 \%$ more area add 01 . Time sub-score was computed by using continuous cultivation practice as 1, 2, 3, 4 for the number of years and 5 for continuous cultivation practice up to 5 years or more. Thus the scores could range from 1-15 where 1 indicated lowest adoption and 15 indicated highest adoption of modern varieties potato cultivation.

Fertilizer dose: Fertilizer score is consisted of combined scores of recommended or over six fertilizers dose score of Urea, Triple Super Phosphate (TSP), Muriate of Potash (MP), Gypsum, Zinc Sulphate and cow dung and scored as 4, 3, 2 and 1 for recommended dose. Also 0, 1, 2 and 3 for double, three-fourths, half, or quarter for the over dose respectively. So, six fertilizer full dose scored 6 by $4=24$ and double dose scored 6 by $0=0$. The score could range from 0-24.

Fertilizer application method: The recommended fertilizer application methods is considered as the basal dose as applied by before land preparation (broadcast), at the time of final land preparation (broadcast) or in fertilizer furrows scored as 0 , 1 and 2 and later dose application for not used, Top dressing and side dressing/spraying (for Zinc fertilizer) scored as 0,1 and 2. Thus the score could range from $0-4$.

Irrigation: Irrigation score of a respondent was computed on the basis of the number like no irrigation, one time irrigation, 2 times irrigation, 3 times irrigation and 4 or more times irrigation with the corresponding score of $0,1,2,3$ and 4 respectively.

Plant protection measures: Recommended six types of plant protection like seed treatment, soil treatment, insect control, disease control, seed sorting, suberization. In addition proper care of aeration and light for the potato fields and stores of tuber seeds was considered as a way of prevention of seed quality control, against the extent of measurement as no treatment, occasional treatment \& necessarily treatment with marking of $0,1 \& 2$ accordingly. The seven sub-scores as told above collectively constituted the plant protection score. Each of the seven subscores could range from 0 to 2 . Therefore, the plant protection score could range from 0 to 14, where 0 indicated no adoption and 14 indicated high adoption.

Use of quality seed : Score were assigned for certified or Bangladesh Agricultural Development Corporation seeds, self produced/own seeds, collected from fellow farmer's seed, seed from other nearest sources and seed collected from unknown person or open market weighed as 5, 3, 2, 1 \& 0 accordingly. Thus Seed score could range from 0 to 5 , where 0 indicated non adoption of quality seed and 5 indicated high adoption. 
Intercultural operation: A list of intercultural operations as weed control, mulching, roughing, removal of virus affected plant, breaking of soil clods, rodent control \& earthing up were assigned as of plant protection measures with corresponding extent of measurement of nature of action taken as no, occasional and according to necessity and weighed as o, 1 and 2 respectively

Planting time: The scale used for computing the planting time score as last week of October to mid November, mid November to November and after November as scored of 0,1 and 2 respectively and where 0 indicated non adoption of optimum planting time and 2 indicated high adoption.

Seed size score: According to the recommendation of potato scientists, the following scale of tuber cut into 2 pieces, tuber cut into 3 to 4 pieces and tuber cut into more than 4 pieces weighed as $2,1 \& 0$. Seed size score could range from 0 to 2, where 0 indicated non adoption of appropriate seed size and 2 indicated high adoption.

Planting space: Spacing score consisted of two sub-scores, namely line to line sub-score 23-24 inch, 20-22 inch and less than 20 inch scored as 2, 1\&0; and plant to plant sub-score5-6, 3-4 \& less than 3 inch weighed as 2, 1 \& 0 . Spacing score was obtained by adding its two sub-scores as told above. Each of the two subscores could range from 0 to 2 . Therefore, spacing scores of the respondents could range 0 to 4 , where 0 indicated non-adoption of recommended spacing and 4 indicated high adoption.

Overall adoption score of all technologies: Thus the overall scores of adoption of potato production technologies could range from 0-94 (Table 1), where 0 indicated no adoption and 94 remarked for peak of adoption. But this range of adoption definitely found higher than 1 and below from 94 which was real calculated range for measuring actual elasticity of adoption. And there by, the elasticity was categorized as low, medium and high according to their range of score distribution as found as minimum to maximum level.

Table 1. Scoring system of adoption technologies.

\begin{tabular}{|l|c|}
\hline Item of technologies & Range of Scours \\
\hline (i) Well land preparation & $0-6$ \\
(ii) Cultivation of modern variety & $1-15$ \\
(iii) Fertilizer dose & $0-24$ \\
(iv) Fertilizer application method & $0-4$ \\
(v) Irrigation & $0-4$ \\
(vi) Plant protection measures & $0-14$ \\
(vii) Use of quality seed & $0-5$ \\
(viii) Intercultural operations. & $0-14$ \\
(ix) Planting time & $0-2$ \\
(x) Seed size & $0-2$ \\
(xi) Planting space & $0-4$ \\
\hline Total 11 technologies & $0-94$ \\
\hline
\end{tabular}




\section{Results and discussion}

For measuring the adoption of modern variety potato production technologies by the growers in the study area, the researcher considered 11 technologies for modern variety potato production. Cumulative results of adoption of 11 technologies were considered to measure overall adoption in different ways which discussed in methodology part. Adoption of these 11 technologies along with their comparative adoption as well as overall adoption has been cited sequentially as follows.

\section{Adoption of well land preparation}

Soil fertility and land productivity is followed by well prepared land through successive plowings, with associated harrowing and mixing with manures and fertilizers. Eliminating all root-weeds is desirable during land preparation. Computed land preparation scores as a part of adoption of potato production technologies by the respondents ranged from 2.5 to 06 against a possible score of 1 to 6 . The mean, standard deviation and co-efficient of variation of this calculated scores were 5.07, 0.96 and 0.93 respectively. Based on adoption of well prepared land scores, the respondent were classified in to three categories as shown in Table 3. Table 3 shows that 49.13 percent of the potato growers had high adoption of well prepared land compared to 36.63 percent medium and 14.22 percent having low adoption. The presented data also revealed that more than fifty percent (50.85\%) potato growers had medium to low adoption of well land preparation. Correct potato husbandry can be an arduous task in some circumstances but a well prepared land along with a little grace from the weather is a good beginning of underground tuber formation and growth from planted quality seed of modern variety.

\section{Adoption of modern variety cultivation}

Genetically improved line of potato is the basis of modern variety which is the key factor to expect higher yields. Variety adoption score was measured on the basis of the nature of one's use of different varieties within his full capacity. Thus modern variety cultivation score consisted of two sub-scores, namely, time sub-score and area sub-score. A computed combination of these two sub-scores for adoption of high yielding modern potato varieties of the respondents ranged from 04 to 15 against a possible score of 1 to 15. The mean, standard deviation and co-efficient of variation of this calculated scores were 11.42, 2.67 and 7.13 respectively. Based on adoption of modern variety cultivation scores, the respondent were classified into three categories as sown in Table 2. Data presented in Table 2 indicates that 43.10 percent of the potato farmers had medium adoption of modern variety cultivation compared to 17.24 percent low and 39.66 percent having high adoption. This finding has similarity with the findings of Muttaleb (1995). Area coverage and continuation of cultivation of any high yielding modern variety is a very important issue to maximize a sustainable production. More than sixty percent (60.34\%) having medium to low adoption shows a scope of increasing potato field giving importance of it's continued area expansion to raise total production. So, it is drawing an attention of extension authorities for their devotion in this regard. Modern variety cultivation is usually adopted due to it's high amount of production per unit area which is conditional to optimum nutrients availability for the planted crop by using balanced fertilizer doze. 
Table 2. Distribution of farmers on the basis of adopted technologies.

\begin{tabular}{|c|c|c|c|c|c|}
\hline \multirow{2}{*}{$\begin{array}{c}\text { Technologies for } \\
\text { adoption }\end{array}$} & \multirow{2}{*}{ Adoption categories (scores) } & \multicolumn{2}{|c|}{ Potato growers } & \multirow{2}{*}{ Mean } & \multirow{2}{*}{$\begin{array}{l}\text { Standard } \\
\text { deviation }\end{array}$} \\
\hline & & Number & Percent & & \\
\hline \multirow{3}{*}{$\begin{array}{l}\text { Well land } \\
\text { preparation }\end{array}$} & Low adoption $(2.5-3.66)$ & 33 & 14.22 & \multirow{3}{*}{5.07} & \multirow{3}{*}{0.96} \\
\hline & Medium adoption $(3.7-5.0)$ & 85 & 36.63 & & \\
\hline & High adoption (above 5.00) & 114 & 49.13 & & \\
\hline \multirow{3}{*}{$\begin{array}{l}\text { Cultivation of } \\
\text { modern variety }\end{array}$} & Low adoption (04 - 08) & 40 & 17.24 & \multirow{3}{*}{11.42} & \multirow{3}{*}{2.67} \\
\hline & Medium adoption $(09-12)$ & 100 & 43.10 & & \\
\hline & High adoption (above 12) & 92 & 39.66 & & \\
\hline \multirow[t]{3}{*}{ Fertilizer dose } & Low adoption (3-10) & 62 & 26.72 & \multirow{3}{*}{13.35} & \multirow{3}{*}{4.49} \\
\hline & Medium adoption (11-17) & 132 & 56.90 & & \\
\hline & High adoption (18-23 ) & 38 & 16.38 & & \\
\hline \multirow{3}{*}{$\begin{array}{l}\text { Fertilizer application } \\
\text { method }\end{array}$} & Low adoption (0.25-1.25) & 26 & 11.20 & \multirow{3}{*}{2.24} & \multirow{3}{*}{0.78} \\
\hline & Medium adoption (1.26-2.75) & 131 & 56.47 & & \\
\hline & High adoption (2.76-4.00) & 75 & 32.33 & & \\
\hline \multirow[t]{3}{*}{ Optimum irrigation } & Low adoption (2) & 6 & 2.59 & \multirow{3}{*}{3.61} & \multirow{3}{*}{0.53} \\
\hline & Medium adoption (3) & 77 & 33.19 & & \\
\hline & High adoption (4) & 149 & 64.22 & & \\
\hline \multirow{3}{*}{$\begin{array}{l}\text { Plant protection } \\
\text { measures }\end{array}$} & Low adoption (1-5) & 27 & 11.64 & \multirow{3}{*}{8.08} & \multirow{3}{*}{2.32} \\
\hline & Medium adoption (6-10) & 175 & 75.43 & & \\
\hline & High adoption (11 and14) & 30 & 12.93 & & \\
\hline \multirow[t]{3}{*}{ Use of quality seed } & Low adoption (01-2.33) & 21 & 9.05 & \multirow{3}{*}{3.39} & \multirow{3}{*}{0.86} \\
\hline & Medium adoption (2.34-3.66) & 128 & 55.17 & & \\
\hline & High adoption (above3.66) & 83 & 35.78 & & \\
\hline \multirow{3}{*}{$\begin{array}{l}\text { Intercultural } \\
\text { operations }\end{array}$} & Low adoption $(3-7)$ & 27 & 11.64 & \multirow{3}{*}{9.97} & \multirow{3}{*}{2.23} \\
\hline & Medium adoption $(8-11)$ & 137 & 59.05 & & \\
\hline & High adoption $(12-14)$ & 68 & 29.31 & & \\
\hline Planting time & Low adoption (0.5-1.0) & 104 & 44.83 & & \\
\hline & Medium adoption (1.1-1.5) & 30 & 12.93 & 1.45 & 0.50 \\
\hline & High adoption (1.51-2.0) & 98 & 42.24 & & \\
\hline Seed size & Low adoption (01-2.0) & 134 & 57.76 & & \\
\hline & Medium adoption (2.1-3.0) & 89 & 38.36 & 2.23 & 0.65 \\
\hline & High adoption (3.1-4.0) & 09 & 03.88 & & \\
\hline Planting spacing & Low adoption (01-2.0) & 160 & 68.96 & & \\
\hline & Medium adoption (2.1-3.0) & 52 & 22.41 & 2.35 & 0.61 \\
\hline & High adoption (3.1-4.0) & 20 & 08.62 & & \\
\hline
\end{tabular}

Adoption of balanced fertilizer dozes

Computed balanced fertilizer doze scores as a part of adoption of potato production technologies by the respondent potato farmers ranged from 3 to 23 against a possible score of 0 to 24 . The mean, standard deviation and co-efficient of variation of this calculated scores were 13.35, 4.49 and 20.22 respectively. Based on adoption of balanced fertilizer doze scores, the respondents were classified into three categories as sown in Table 2. Data presented in the Table 2 indicates that majority had medium (56.90\%) adoption compared to 26.72 percent low and 16.38 percent had high adoption of balanced fertilizer doze as a factor of adoption of modern potato technologies. Observed scores also revealed that, more than four-fifths (83.62\%) portion of the farmers belonged to low to medium 
category which is more or less similar to the study of Muttaleb (1995) and Hasan (2003). Therefore, the present findings are strengthening with said previous studies. It might be due to lack of awareness of soil test for plant nutrient requirements, lack of appropriate training and knowledge of fertilizer use or overdose and even application method of recommended fertilizers.

\section{Adoption of recommended fertilizer application method}

Fertilizer application method scores of the potato grower respondents could range from 0 to 4 . Computed scores of the respondents, however ranged from 0.25 to 4 . With an average of 2.24, standard deviation and co-efficient of variation are 0.78 and 0.61 respectively. The potato farmers were classified into three categories on the basis of adoption of recommended fertilizer application method score as shown in the Table 2. The presented data in Table 2 shows that 56.47 percent respondents had medium adoption of recommended fertilizer application method compared to 11.20 percent having low adoption and 32.33 percent having high adoption. Data also revealed that more than two-thirds (67.67\%) respondents had medium to low adoption. Therefore, special attention needs to be given to help the farmers in increasing adoption of recommended fertilizer application method. Research has proved that recommended fertilizer application method reduces cost of production \& keeping support of soil health and ensure maximum intake of nutrients by the planted crop by minimizing system lose of leaching, evaporation, percolation, drainage etc. through reserved soil moisture or rainfall or irrigation.

\section{Adoption of optimum irrigation}

Computed irrigation scores as a part of adoption of potato production technologies by the respondents ranged from 2 to 4 against a possible score of 1 to 4 . The mean, standard deviation and co-efficient of variation of this calculated scores were 3.61, 0.53 and 0.28 respectively. Based on optimum irrigation scores, the respondent were classified into three categories as shown in Table 2.Table 2 shows that 64.22 percent of the potato growers had high adoption of optimum irrigation compared to 33.19 percent medium and 2.59 percent having low adoption. The presented data also revealed that majority had high adoption of optimum irrigation. Muttaleb (1995) also found the same trend in his study. Research has proved that irrigation can increase the yield of potato to a remarkable extent (BARI, 2000). Effect of irrigation will be much higher if the adoption of other recommended practices or technologies are also increased like plant protection measures.

\section{Adoption of plant protection measures}

The computed plant protection measures scores of the potato respondents ranged from 1 to 14 against the possible range of 0 to 14 . Based on the observed scores the mean, standard deviation and co-efficient of variation were 8.08, 2.32 and 5.40 respectively. On the basis of score the respondent were classified into three categories as shown in Table 2. Data presented in the Table 2 indicates that the highest proportion (75.43\%) of the farmers had medium adoption compared to 11.64 percent had low and 12.93 percent had high adoption of plant protection measures. The findings show that highest proportion (88.36\%) of the respondents had medium to high adoption. The result is promising as found by Muttaleb (1995) and Hasan (2003). In view of the importance of plant protection measures it is 
necessary for the agricultural extension service to take effective steps to ensure judicious use of any chemical pesticide or herbicide as a measure of plant protection for conservation of environment and quality production.

\section{Adoption of quality seed}

Adoption scores of quality potato seed of the farmers ranged from 1 to 5 , against the possible range of zero (0) to 5 . The average score was found to be 3.39 with the standard deviation and co-efficient of variation were 0.86 and 0.74 respectively. Based on the quality seed scores, the respondent were classified into three categories as shown in Table 2. Data presented in the Table 2 indicates that majority of the respondents had medium adoption of quality potato seed compared to 9.05 percent low and 35.78 percent high adoption of quality potato seed. The data also reveals that above two-thirds of the potato growers had medium to low adoption. Seed is a basic indicator of expected yield per unit area. No other factor can ensure maximum production until quality seed is planted. Therefore, yield of potato would be lower among a considerable section of potato growers due to lower adoption of quality seed. So, DAE should have more initiatives to make a better linkage between farmers and quality seed providing agencies like BADC.

\section{Adoption of intercultural operations}

Intercultural Operations scores of the potato grower respondents could range from 0 to 14 . Computed scores of the respondents, however ranged from 3 to 14 with an average of 9.97 and standard deviation and co-efficient of variation 2.23 and 4.99 respectively. The potato farmers were classified into three categories on the basis of observed scores of adoption of intercultural operations as shown in the Table 2. The presented data in Table 2 shows that 59.05 percent respondents had medium adoption of intercultural operations as compared to 11.64 percent having low adoption and 29.31 percent having high adoption. Data also revealed that about three-fourths (70.69\%) respondents had medium to low adoption. Therefore, special attention needs to be given to help the farmers in increasing adoption of intercultural operations as recommended technology. It is also appreciated that prevention (intercultural operations) has better response to reduce protection (use of expensive chemicals) cost and increase of quality and quantity of timely planted potato.

\section{Adoption of planting time}

Scores of computed planting time as observed by the respondent potato farmers ranged from 0.5 to 2.0 against the possible range of 0 to 2, the mean being 1.45 with standard deviation and co-efficient of variation were 0.50 and 0.25 respectively. The potato farmers were classified into three categories on the basis of observed scores of adoption of planting time as shown in the Table 2. The presented data in Table 2 shows that 44.83 percent respondents had low adoption of optimum planting time of potato as compared to 42.24 percent having high adoption and 12.93 percent having medium adoption. Data also revealed that majority of 57.76 percent respondents had medium to low adoption. Research has proved that optimum planting time reduce attack of various insects and diseases and increase the yield of potato. Effective extension service for ensuring initial inputs of cultivation might improve the adoption of planting time. 


\section{Adoption of recommended seed size}

Recommended seed size scores of the potato grower respondents could range from 0 to 4 . Computed scores of the respondents, however ranged from 1 to 4 with an average of 2.34 and standard deviation and co-efficient of variation 0.65 and 0.43 respectively. The potato farmers were classified into three categories on the basis of observed scores of adoption of recommended seed size as shown in the Table 2. The presented data in Table 2 shows that 57.76 percent respondents had low adoption of recommended seed size as compared to 38.36 percent having medium adoption and 3.88 percent having high adoption. Research on potato indicates that recommended seed size has a favourable influence on potato yield. But 96.12 percent of the potato farmers had low to medium adoption. Effective extension training \& educational program might be a helpful measure to improve the present level.

Adoption of recommended plant spacing

Adoption scores of recommended spacing of the farmers ranged from 1 to 4 , against the possible range of zero (0) to 4 . The mean was found to be 2.35 with the standard deviation of 0.61 and co-efficient of variation 0.37. Based on observed spacing scores, the respondents were classified into three categories as sown in Table 2. Data presented in the Table 2 indicates that majority of the respondents had low adoption of spacing scores compared to 22.41 percent medium and 08.62 high adoption of spacing scores. The data also reveals that above nine-tenths (91.37\%) of the potato growers had medium to low adoption. Seed is a basic indicator of expected yield per unit area. So, finding of the study indicates that adoption of potato spacing is remaining behind which would be necessary to improve through effective result demonstration.

\section{Overall adoption of modern potato production technologies}

In order to have a clear understanding of the combined adoption of the eleven selected potato production technologies, an overall adoption score was computed for each of the respondent by adding the score of 11 modern potato production technologies. Possible range of the overall adoption score of the study respondent farmers could range from 0 to 96, where 0 indicated minimum adoption and 96 indicated maximum adoption of potato production technologies. Computed overall adoption scores of the farmers ranged from 45 to 80.50 . The mean value is being 63.32 with standard deviation and co-efficient of variation 7.92 and 62.70 respectively. Based on the observed scores, potato grower farmers were classified into three categories such as "low" adoption, "medium" adoption and "high" adoption as shown in Table 3.

Table 3. Distribution of the farmers according to their overall adoption of modern potato technologies.

\begin{tabular}{|l|c|c|c|c|}
\hline \multicolumn{1}{|c|}{$\begin{array}{c}\text { Categories according to overall } \\
\text { adoption (scores) }\end{array}$} & \multicolumn{2}{|c|}{ Potato growers } & \multirow{2}{*}{ Mean } & $\begin{array}{c}\text { Standard } \\
\text { Deviation }\end{array}$ \\
\cline { 2 - 3 } & Number & Percent & & \\
\cline { 1 - 3 } Low adoption (45-57) & 55 & 23.71 & & \\
\cline { 1 - 3 } Medium adoption (57.01-68.83) & 116 & 50.00 & \multirow{2}{*}{63.32} & \multirow{2}{*}{7.92} \\
\hline High adoption (68.84-80.50) & 61 & 26.29 & & \\
\hline Total & 232 & 100 & & \\
\hline
\end{tabular}


Data contained in Table 3 indicates that majority (46.55\%) had medium adoption compared to high (29.74\%) and low (23.71\%) adoption. But almost three-fourths (73.71\%) of the farmers had low or medium adoption. Potato as a short duration starchy vegetable crop might have scope of alternative source of staple food would play a significant role in meeting the increasing demand of rice and wheat grain.

Comparative adoption of eleven selected production technologies of potato production practices

For comparing the extent of adoption of 11 selected technologies as a factor of adoption determinants it was required to compute an adoption index for each of the eleven technologies. The adoption index for a certain technology was computed by using the following formula: Adoption index $=\mathrm{Pn} \times 0+\mathrm{Pl} \times 1+\mathrm{Pm}$ $\times 2+\mathrm{Ph} \times 3$

$\mathrm{Pn}=$ Percentage of farmers having no adoption.

$\mathrm{Pl}=$ Percentage of farmers having low adoption.

$\mathrm{Pm}=$ Percentage of farmers having medium adoption.

$\mathrm{Ph}=$ Percentage of farmers having high adoption .

Adoption index of a technology could be range from 0 to 300, where 0 indicates no adoption and 300 for high adoption. However, the computed indices of the eleven modern technologies ranged from 0 to 300. The eleven modern technologies have been arranged in rank order on the basis of their adoption indices in Table 4. Analysis of data in Table 4 indicates that among the extent of adoption of modern eleven technologies recommended irrigation was at top highest ranking by the adoption index of 261. Muttaleb (1995) also found the similar findings in his study. The adoption index of well land preparation, use of quality seed, modern variety cultivation, fertilizer application method, inter cultural operations, plant protection measures were 234, 227, 222, 221, 218 and 201 respectively. But below two-thirds of adoption index scores were found in planting time, fertilizer doze, seed size and plant spacing 200, 190, 146 and 140 respectively.

Table 4 shows the rank order of modern variety potato production technologies by their adoption index. Adoption of optimum irrigation followed by well land preparation was top ranking.

Table 4. Ranking order of modern variety potato production technologies.

\begin{tabular}{|c|l|c|c|}
\hline Sl. No. & \multicolumn{1}{|c|}{ Modern technologies } & Adoption index & Rank order \\
\hline 1. & Well land preparation & 234 & 2 \\
\hline 2. & Cultivation of modern variety & 222 & 4 \\
\hline 3. & Fertilizer doze & 190 & 9 \\
\hline 4. & Fertilizer application method & 221 & 5 \\
\hline 5. & Optimum irrigation & 261 & 1 \\
\hline 6. & Plant protection measures & 201 & 7 \\
\hline 7. & Use of quality seed & 227 & 3 \\
\hline 8. & Intercultural operations & 218 & 6 \\
\hline 9. & Planting time & 200 & 8 \\
\hline 10. & Seed size & 146 & 10 \\
\hline 11. & Planting spacing & 140 & 11 \\
\hline
\end{tabular}


It might be due to the desire of predisposition of crop field for tuber growth under the soil. Optimum soil moisture is interlinked with tilth condition and water supply by sufficient irrigation. Good seed is pre-condition of good yield but usually seed supply is not ensured due to out of reach by the farmers. Adoption of seed size and plant spacing were at lowest ranking. The remaining technologies were adopted with the priority as conceived by the knowledge of the farmers.

Among 11 technologies optimum irrigation, well land preparation, use of quality seed and extent of modern variety cultivation ranking leading position. Fertilizer application method, intercultural operations and plant protection measures are remaining in middle position. The following technologies like planting time, fertilizer dose, seed size and planting space are remaining in behind position. Overall adoption of majority of fifty percent of the farmers in the study area had medium adoption while the rest is about equal sharing of low (24\%) and high (26\%). Thus it may be concluded that adoption variations in different technologies will not be improved unless effective steps are taken to increase farmers' exposure to get benefits of using such technologies as per recommendations.

\section{References}

BBS (Bangladesh Bureau of Statistics). 1982. Statistical Year Book of Bangladesh. Bangladesh Bureau of Statistics, Dhaka.

Bhuiyan, N.I., Parl, D.N.R. \& Jabbar, M.A. 2002. Feeding the extra million by 2025. challenges for rice research and extension in Bangladesh. Keynote paper presented at national workshop on rice research and extension 2002. Bangladesh Rice Research Institute, Gazipur. 29-31 January, 2002.

BARI (Bangladesh Agricultural Research Institute). 2000. Krishi project hatboi. Bangladesh Rice Research Institute, Gazipur.

FAO. 2002. FAO Production Yearbook.. Vol. 56, Food and Agricultural Organization, Rome.

Farukh, A.H.M. 2007. High value food crop production technology training module. Northwest Crop Diversification Project, Dhaka: 19-22.

Hasan, M.M. 2003. Adoption of recommended potato cultivation practices by the farmers in some selected areas of Rajshahi district. M.S. thesis. Department of Agricultural Extension Education. Bangladesh Agricultural University: 8-9.

Islam, M.M. 1993. Adoption of improved practices in potato cultivation by the potato farmers of Sonatola union under Bogra district. M.Sc. (Ag. Ext. Ed.) thesis, Department of Agricultural Extension Education, Bangladesh Agricultural University: 65-66.

Muttaleb, M.A. 1995. Farmers' preference matching and adoption of modern rice cultivation practices in haor area of northeast Bangladesh. Ph.D. thesis. Department of Agricultural Extension Education. Bangladesh Agricultural University: 208-212.

Rashid, M.M. 1987. Potato production in Bangladesh. Consultancy report prepared for FAO Regional Office for Asia and the Pacific, Bangkok. Tuber Crops Research Center, Bangladesh Agricultural Research Institute, Gazipur: 1-11.

Van-Diepan, M.R. 2003. Netherlands catalogue of potato varieties. Netherlands Potato Consultative Foundation, The Netherlands: 4-5. 